\title{
METAANALYSE
}

\section{Arbeitsstress ist kein Risikofaktor für Krebs}

Stress im Beruf geht nicht mit einem höheren Risiko einher, an Krebs zu erkranken. Das hat eine Metaanalyse von zwölf europäischen Kohortenstudien ergeben.

5,0\% der Studienteilnehmer erkrankten während des Beobachtungszeitraums (zwölf Jahre) an Krebs. Ein Zusammenhang mit Arbeitsstress war nicht zu erkennen, weder für das Gesamtrisiko noch bezogen auf die genannten Tumorentitäten. Damit ist es laut den Forschern unwahrscheinlich, dass die berufliche Belastung einen wichtigen Risikofaktor für die Krebsentstehung darstellt.

BMJ 2013; DOI: 10.113/bmj.f165

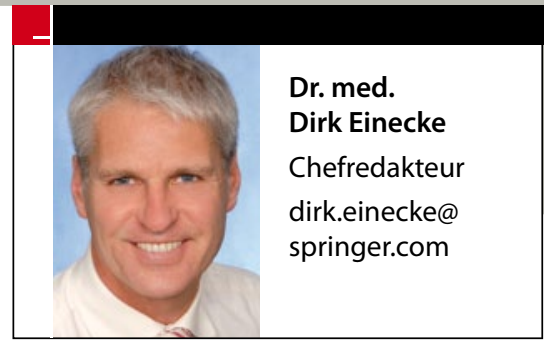

BISSVERLETZUNGEN IM GESICHT Bei Kindern ist oft der Familienhund schuld

Wenn Kinder von einem Hund attackiert werden, gehört der Angreifer meistens zur Familie und ist oft selbst noch jung. Diese Beobachtung haben Ärzte des Alder Hey Children's Hospital in Liverpool gemacht. In den Jahren 2001 bis 2011 mussten dort 436 Kinder behandelt werden, weil ein Hund sie in Gesicht oder Hals gebissen hatte. Das mediane Alter der Opfer lag bei sechs Jahren. Am häufigsten hatten die Hunde die Kinderlippen zerfleischt (46\%). Bei vielen waren auch Ohren (23\%) und Wangen (15\%) malträtiert worden.

$70 \%$ der Bissverletzungen hatten sich in den eigenen vier Wänden ereignet. Fast alle Hunde (98\%) waren den Kindern bekannt gewesen, in 55\% der Fälle handelte es sich sogar um den Familienhund. Besonders aggressiv sind Staffordshire Bullterrier. 18\% der Verletzungen waren durch diese Hunde verübt worden.

Clinical Otolaryngology 2013; online: 7 FEB 2013 DOI: 10.1111/coa.12094

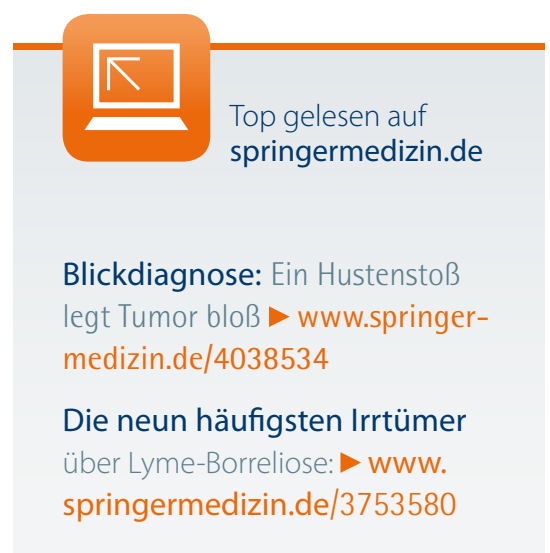

